\title{
ETNOGRAFÍA MÓVIL: UNA POSIBILIDAD METODOLÓGICA PARA EL ANÁLISIS DE LAS IDENTIDADES DE GÉNERO EN FACEBOOK
}

\author{
Ana Paulina Gutiérrez Martínez \\ Facultad de Estudios Superiores de Cuautla \\ Universidad Autónoma del Estado de Morelos
}

\section{RESUMEN}

A partir de una investigación con personas trans femeninas de la ciudad de México, en este artículo reflexiono sobre la etnografía móvil como una posibilidad metodológica para el análisis socioantropológico del género, las identidades, internet y los tránsitos que los caracterizan. Internet y las redes sociales cobran cada vez mayor importancia en la vida cotidiana de las personas, de manera que la virtualidad ha dejado de ser un escenario de ciencia ficción y se ha convertido en instrumento de comunicación cotidiana y en espacio social. Las redes sociales en internet no son espacios fijos sino que se distinguen por los tránsitos continuos de los usuarios dentro y fuera de línea, mismos en los que se define el papel de la identidad de las personas.

\section{PALABRAS CLAVE}

Género, Identidad, Trans, Internet, Etnografía, Facebook

\section{ABSTRACT}

In this paper I consider the mobile ethnography as a methodological possibility for the socio-anthropological analysis of gender, identities, internet and the traffic that characterizes all these. This proposal is based on a research work with trans people $(\mathrm{MtF})$ from México City. Internet and social media gain importance in daily life of people. Virtuality is no more a science fiction periphery but a daily communication instrument and a social space. Social media are not firm spaces but characterized because of the constant traffic online-offline of users. Gender identity plays a central role in these movements. 
KEY WORDS

Gender, Identity, Transgender, Internet, Ethnography, Facebook 


\section{INTRODUCCIÓN}

El objetivo de este artículo es reflexionar sobre algunas posibilidades metodológicas para el análisis del género y las identidades en internet. Este texto forma parte de una investigación etnográfica más amplia sobre identidades trans femeninas, sociabilidades, internet y tránsitos de género en la ciudad de México (Gutiérrez, 2015). El trabajo de campo se realizó en un periodo de tres años, de 2010 a 2013, con una red diversa de personas trans femeninas, ${ }^{1}$ en espacios de encuentro como fiestas, discotecas, centros culturales, calles de la ciudad de México y Facebook, la red social de internet en la que se concentró parte del análisis.

Después de la primera fiesta trans a la que fui invitada, el número de mis amistades trans femeninas en Facebook se incrementó. Algunas de las asistentes me reconocieron y enviaron una solicitud de amistad. Yo hice lo mismo cuando el perfil de alguna conocida aparecía como sugerencia de Facebook. De esta manera, la red de personas trans que había contactado en los primeros meses de campo, se desplazó a este espacio virtual.

Comencé entonces a integrar en mi perfil de Facebook a más amigas trans, ${ }^{2}$ así como algunas

1 Por personas trans femeninas me refiero a personas que nacieron con pene y testículos y fueron socializadas como varones, pero que se han identificado en algunos momentos de su vida o se identifican a sí mismas en la actualidad como mujeres y quieren ser vistas y tratadas como tales. Estas personas pueden transitar durante su vida entre los dos polos del orden de género: masculino y femenino o "establecerse" de manera definitiva en alguno de ellos, ya sea de manera práctica o como una aspiración. Al acercarnos a las distintas narrativas autobiográficas, encontramos diversidad de recursos y formas clasificatorias que no se limitan a las categorías travesti, transgénero y transexual, que se utilizan con frecuencia para nombrar a las personas trans femeninas.

2 En Facebook el término amigo(a) hace referencia a los organizaciones no gubernamentales, especialistas de diversas disciplinas y activistas relacionados con el tema trans. Decidí utilizar mi cuenta personal de Facebook sin mayor reflexión al respecto, como quien da un número de teléfono para mantener contacto con sus interlocutores. Algunos meses más tarde, cuando la red empezó a crecer y las interacciones se tornaron constantes, me sentí rebasada por la información. Me di cuenta que uno de los espacios que utilizaba para distraerme y tomar la necesaria distancia de la investigación, estaba completamente invadido por la misma.

Pensé que sería mejor abrir otra cuenta exclusiva para la investigación. Intenté hacerlo pero me topé con complicaciones técnicas que ponían en riesgo mis contactos y decidí no mover nada. A partir de ese momento me di cuenta de todo lo que ignoraba sobre Facebook. Yo utilizaba esta red social de manera ingenua, sin percatarme de quién tenía acceso a mi información y a la de mis contactos. Comencé a ser consciente de los usos que yo misma le daba a esta herramienta en mi vida cotidiana. Noté el tiempo que invertía en ella, los materiales que compartía y las formas en que interactuaba con mis contactos. De esta manera, se me ocurrió utilizarla no sólo para mantener comunicación con mis interlocutoras, sino para observar las interacciones en torno a lo trans. Decidí pensar Facebook como un espacio urbano más, en donde no es deseable, ni posible, aislar las relaciones sociales para observarlas de manera "pura" o imparcial.

Mi papel como investigadora era fundamental para que ciertas interacciones sucedieran y yo pudiera

contactos que conforman la red de los usuarios. 
realmente formar parte de este espacio social. Puse atención en el rapport dentro de Facebook. ¿Qué es lo que hacemos los investigadores sociales para establecer una relación de confianza con nuestros interlocutores? ¿Cómo hacerlo en un espacio virtual? Comencé a comunicarme directamente con las personas trans femeninas que había conocido en otros espacios de la ciudad de México, y que ahora eran mis amigas en Facebook. Al recibir la confirmación de amistad les devolvía un mensaje privado o una publicación en sus muros agradeciendo la aceptación de mi amistad virtual. Las felicitaba en sus cumpleaños, le daba "me gusta" a sus fotos y las comentaba, y cuando ellas hacían lo mismo con las mías, les regresaba el comentario. Las relaciones que establecía en Facebook se asemejaban a las que tenía en otros espacios del campo de estudio: nos saludábamos, conversábamos, bromeábamos y polemizábamos. Compartíamos también materiales de interés que tenían que ver con la investigación y con otros temas relevantes para mis interlocutoras y para mí misma. Varias de ellas me agregaron a grupos públicos con temas de interés trans, que fueron aumentando en número cada día.

A fin de hacer explícito el objetivo de la investigación y presentarme formalmente con mis amigas trans en Facebook (que para ese momento superaban los 100 perfiles), decidí abrir un grupo privado. Incluí en él a todas las personas trans femeninas de mi red. A pesar de ser privado, el grupo permitía que todos los miembros agregaran a quienes desearan. Esto facilitó que el número de personas adscritas creciera hasta llegar a 130 en seis meses. ${ }^{3}$ El grupo funcionó como una plataforma

3 Fue también a través de este grupo que compartí una encuesta utilizada por las personas trans, tanto femeninas como masculinas, para compartir información de todo tipo: fotografías, reflexiones, anécdotas e invitaciones a eventos. A través de este grupo, fue que realicé el análisis en Facebook con base en dos elementos discursivos: las fotografías de perfil y los discursos normativos sobre ser trans o mujer trans.

Mientras transcurría el trabajo de campo en Facebook, comencé a preguntarme sobre las formas posibles de estudiar estos espacios cuando se investiga sobre género. ¿Cómo debería delimitar el campo de estudio y dar cuenta de sus continuas transformaciones? ¿Cómo poner en acción el método que me permitiría observar, registrar y analizar el movimiento de las personas y de las herramientas tecnológicas? Estas preguntas fueron un punto de partida para entrar en el campo, mismo que se caracterizaba de manera importante por los tránsitos de las personas, tránsitos relacionados no sólo con el género, sino también con la presencia dentro y fuera de línea. Yo misma como usuaria de Facebook formaba parte de estos tránsitos. Y como investigadora efectuaba también tránsitos de otro tipo: los desplazamientos teóricos y

que recababa información general sobre la vida cotidiana de las personas trans de la ciudad de México. Si bien en este texto no incluyo la información de dicha encuesta, la menciono por ser uno de los elementos que permitió estar en contacto con mis interlocutoras en Facebook. Parte de las 130 personas del grupo respondieron la encuesta, no todas. El cuestionario fue difundido por algunas de mis interlocutoras en su propio perfil de Facebook y por correo electrónico, lo que trajo como consecuencia algunos cuestionarios respondidos por personas ajenas al grupo. En total recibí 172 cuestionarios respondidos por completo, de los cuales 113 corresponden a personas que residen en la ciudad de México y Área Metropolitana $(\mathrm{N}=113)$. El resto corresponden a personas que viven en otros estados de la República y por tanto no fueron incluidos en la investigación. 
metodológicos necesarios para la investigación en este campo de estudio.

El campo de las redes sociales en internet ha sido, hasta ahora, poco estudiado por las ciencias sociales. En los últimos años se han escrito algunos textos académicos en el campo de la psicología, las ciencias de la comunicación, la sociología y la antropología. Los principales tópicos versan sobre internet en general y, más recientemente, sobre algunas herramientas particulares como los chats, los videojuegos o las redes sociales. También existen algunos estudios sobre el papel de internet y las redes sociales virtuales, como Twitter y Facebook, en movilizaciones políticas y sociales como la Primavera árabe en Túnez y Egipto en 2010 y 2011, el Movimiento 15-M en España, el Movimiento Occupy Wall Street en Estados Unidos, también en el 2011, y el Movimiento \#YoSoy132 en México en el 2012 (Castells, 2009; Cogo y Lopes, 2011; Guzmán, 2013; Chaves Lopes, 2013; Machado, 2007; Mata, 2002; Merino, 2015; Salgado, 2013; Serrano et al., 2014; Taibo, Vivas, Atentas, 2011).

Si bien la producción académica va en aumento, existen todavía escasos textos que profundicen en los aspectos metodológicos de la investigación social en estas plataformas virtuales. Son pocas las referencias teóricas y empíricas sobre un campo de estudio que está en transformación constante y acelerada, y sobre el tipo de relaciones sociales que lo conforman (Domínguez et al., 2007; Gómez, 2002; Gómez y Ardèvol, 2011; Hochman, 2014; Jones, 1999; Manovich, 2014; Picciuolo Valls, 1999; Aguilar y Said, 2010; Tong et al., 2008).

Este contexto permite proponer nuevas formas de investigar las relaciones sociales en internet y recuperar las propuestas metodológicas que no se hacen explícitas en algunas de las aproximaciones a este campo. Es importante insistir que el campo de estudio es particularmente efímero, es decir, sus transformaciones suceden de manera constante y profunda (Gómez 2002: 62; Gutiérrez, 2015: 154). El desarrollo tecnológico acelerado de las últimas dos décadas ha producido un sinfín de posibilidades para el uso de las nuevas tecnologías de la comunicación, ${ }^{4} \mathrm{y}$ con ello múltiples formas de interpretarlas y aproximarse a su estudio. El número de usuarios de distintos estratos sociales, estilos de vida y géneros se ha incrementado como consecuencia del abaratamiento de estas tecnologías, lo cual hace atractivo y pertinente la investigación en campos como la antropología y la sociología.

Las redes sociales cambian constantemente su estructura y presentación. Agregan elementos que permiten a los usuarios interactuar de distintas maneras y vincularse con la creciente cantidad de redes sociales en internet. Al mismo tiempo, los usuarios transitan entre redes virtuales y redes fuera internet, es decir, en espacios sociales ubicados en distintos puntos de la ciudad. Al utilizar las redes en internet, el usuario no se aísla, como se afirma con frecuencia en círculos no especializados en el tema, sino que mantiene los vínculos con las personas, instituciones y espacios que habita fuera de internet (Gutiérrez, 2015; Winocur, 2006).

4 Aunque internet comenzó a desarrollarse en Estados Unidos desde la década de 1960, se sigue incluyendo, junto con la world wide web (www) o red informática mundial, la telefonía móvil, las computadoras, los sistemas operativos, la televisión digital, los reproductores de audio y video, y las consolas de videojuegos - entre otras-, dentro de las nuevas tecnologías de comunicación e información. 
Una de las principales características de las redes sociales en internet es que éstas funcionan como medios masivos de información y comunicación, a la vez que fungen como espacios urbanos que contienen sociabilidades particulares. ${ }^{5}$ Las sociedades y las personas están en constante transformación. El desarrollo tecnológico de las comunicaciones y las estrategias de mercado, por medio de las cuales se masifica esta tecnología, van influyendo en las nuevas formas de organización social y en la producción de subjetividades. Las personas se apropian de estos nuevos espacios, viven, transitan y se transforman con ellos. En este contexto es pertinente conocer de manera profunda y sistemática las formas en que se gestan, despliegan y transforman las relaciones sociales en internet y las redes sociales. ¿Cómo debemos entonces, quienes hacemos investigación social sobre género, aproximarnos a esas realidades? ¿Cómo delimitar el campo de estudio y dar cuenta de dichas transformaciones? ¿Cómo observar, registrar y analizar el movimiento continuo de las personas trans femeninas usuarias de Facebook?

\section{EL ORDEN DE GÉNERO}

\section{Y LAS IDENTIDADES}

A fin de establecer el punto de partida en esta investigación, para hablar de las identidades de género en las redes sociales en internet y las

5 Los espacios son productos sociales que se asientan en ciertos territorios que pueden ser más o menos fijos, es decir, pueden estar localizados y definidos en un sitio particular y no moverse, o pueden aludir a un territorio virtual en constante movimiento, como el ciberespacio. Las sociabilidades, por su parte, son relaciones sociales e interacciones particulares contenidas en ciertos espacios, mientras que lo urbano hace referencia a los procesos sociales que suceden en las ciudades (Gutiérrez, 2015). posibilidades de investigarlas, es necesario definir estos conceptos.

El género es un término que ha nombrado y definido varios aspectos humanos en distintos ámbitos sociales y momentos históricos. Me referiré en este artículo a dos de las formas posibles, pero no únicas, de entender el género. Por un lado, desde una visión esencialista, el género se refiere y se ha referido a las categorías ontológicas de hombre y mujer. Desde esta óptica se utiliza el término género como una propiedad inherente a los seres humanos: las personas tenemos género. Los esencialismos acerca del género no sólo han estado presentes en el sentido común, sino que han sido y son avalados y reproducidos por medio de algunos discursos médicos, sexológicos, académicos y jurídicos. $\mathrm{La}$ idea de que la persona ha definido en la infancia su identidad de género, misma que es inmodificable, y la forma en que algunos especialistas médicos conciben el ideal femenino al que debe aspirar una persona trans femenina, son parte de una visión esencialista del género (Álvarez-Gayou y Mazin, 1979; Barrios y García, 2008; Stoller, 1968) ${ }^{6}$

Por otro lado, se utiliza el género de manera más compleja, como una categoría analítica que refiere a un orden social que atraviesa distintas

6 Antes de las reformas recientes al Código Civil del Distrito Federal y al Código de Procedimientos Civiles del Distrito Federal en donde se establece que el levantamiento de una nueva acta de nacimiento para el reconocimiento de la identidad de género es posible por medio de un trámite en el Registro Civil, era preciso obtener peritajes médicos que avalaran la disforia de género a la que una persona trans tenía que apelar para lograr el levantamiento de la nueva acta. Como parte de estos peritajes se llevaba a cabo la prueba de la vida real, que consiste en probar al médico especialista que la persona sabe moverse en el mundo de acuerdo al género que aspira encarnar y expresar socialmente. 
dimensiones de la vida de las personas, entre las que se encuentran la sexualidad, la identidad y el cuerpo (Butler, 2007; Connell, 1987; Scott, 2008).

La historiadora Joan Scott define el género como una categoría analítica que puede entenderse en dos sentidos: como un elemento constitutivo de las relaciones sociales basadas en la diferencia de los sexos y como una forma primaria de las relaciones simbólicas de poder (Scott, 2008). La autora enfatiza la existencia de cuatro elementos o subpartes del género que se interrelacionan: las representaciones simbólicas, los conceptos normativos, las instituciones y las identidades subjetivas. A partir de las coordenadas de estos cuatro elementos se concibe y configura el poder en distintas sociedades.

Por su parte, la socióloga Raewyn Connell (1987) pone el acento en el carácter colectivo del género. Con ello destaca el carácter estructural del mismo y de la reproducción de la especie (aunque sea de manera potencial y no real en todos los miembros sociales). También define el concepto a partir de la distribución del poder en las relaciones sociales. Para Connell, las prácticas sociales deben ser entendidas como prácticas estructuradas y jerarquizadas por el género. Al hablar de la existencia de un orden jerarquizado $\mathrm{y}$ no igualitario, el poder toma un papel protagónico: atraviesa los distintos aspectos de la vida de las personas y las posibilidades que tienen de acceder a los diversos ámbitos sociales, como el trabajo remunerado, las cúpulas de poder y la educación formal, entre otros.

En este mismo sentido, Judith Butler (2007) plantea que el orden de género organiza las formas de hacerse persona en el mundo social y subjetivo. Dicho orden atraviesa dimensiones como el cuerpo, la sexualidad y la identidad. Para Butler, el género es el resultado de un proceso conformado por prácticas regulatorias complementarias. Mediante este proceso, las personas — miembros de una sociedad estructurada con base en un modelo hegemónico heterosexual-, reciben e inscriben significados culturales en sus cuerpos. La investigadora desarrolla también la idea del carácter performativo del género por medio del cual se constituye, entre otras cosas, la identidad de género de la persona. De acuerdo con Butler, la performatividad del género no es un acto único, como si fuera una actuación calculada, sino que es un proceso que se repite. Es un ritual que consigue su efecto en las personas y en las sociedades, a través de la naturalización de un cuerpo, y, añadiría yo, de los cuatro elementos que menciona Scott en su definición de género.

En este texto sigo la línea teórica de las tres autoras mencionadas, Scott, Connell y Butler, a quienes no les basta definir el género como una construcción social, sino como un proceso de organización social complejo y dinámico. Este proceso, de carácter colectivo, se naturaliza a fin de funcionar y reproducirse, pero al ser histórica y socialmente situado, deja espacio para la transformación.

Utilizo el concepto de género como una forma de organización social, que jerarquiza las identidades de las personas y las relaciones sociales, de acuerdo con la diferencia de los cuerpos en relación con la biología de la reproducción humana y las formas del deseo erótico. Dicho orden de 
género es binario y heteronormativo, es decir, "lo normal" es que existan mujeres y hombres que se relacionen eróticamente entre ellos. Se establecen dos expresiones de género supuestamente opuestas y complementarias, que se encarnan en los cuerpos sexuados de las personas, pero se tejen y reproducen en (y a través de) las representaciones simbólicas, los conceptos normativos, las identidades subjetivas $\mathrm{y}$ las instituciones. Las identidades y las relaciones eróticas que se salen de la norma dicotómica y heterosexual son consideradas antinaturales, anómalas o patológicas. Es decir que la lógica del orden de género se basa en la consideración de la matriz heterosexual como norma para las relaciones sociales y, por lo tanto, para la configuración de las identidades de las personas y sus prácticas.

Bajo esta perspectiva, mi aproximación a las identidades de género de las personas trans femeninas, tanto fuera como dentro de Facebook, fue mucho más dinámica y compleja que si lo entendiera como un atributo construido socialmente sobre una base biológica. El orden de género, al igual que las sociedades en sus distintos aspectos y formas organizativas, se transforma. Esta es la paradoja que permite, por un lado, que los órdenes sociales funcionen por medio de la naturalización de algunas ideas y prácticas, pero por el otro, que puedan ser transformados. Dichas transformaciones son producidas por las personas que cuestionan y dislocan los órdenes sociales en busca de otros sentidos y maneras, alternativas a las hegemónicas (Butler, 2007), de habitar el mundo. El género es un proceso dinámico e inestable. Es un conjunto de tránsitos diversos y complejos, que por fortuna es observable en las redes sociales en internet.

\section{LO TRANS EN FACEBOOK}

Durante mi trabajo de campo en la ciudad de México me encontré con sociabilidades trans muy diversas. Esta diversidad se hacía presente tanto en las observaciones presenciales como en los relatos de mis interlocutoras que aludían a lugares que han sido y siguen siendo fundamentales para las personas trans: las fiestas, los hoteles, las discotecas, las librerías y foros culturales y los chats en internet. Estos últimos se fueron multiplicando y transformando, hasta que derivaron, de alguna manera, en lo que ahora conocemos como redes sociales (Gutiérrez, 2015).

Los usos que mis interlocutoras le dan a Facebook abarcan varias actividades, herramientas y recursos culturales. Algunos de los más frecuentes son hacer contacto con otras personas trans con quienes comparten espacios y experiencias fuera de internet, e intercambiar videos, fotografías e información de diversos temas, entre los que indudablemente se encuentran diferentes aspectos sobre lo trans. Con frecuencia se comparten tutoriales sobre la transición de género de personas trans femeninas y masculinas, así como información sobre salud y derechos humanos. En los últimos meses de trabajo de campo, por ejemplo, buena parte de las publicaciones versaban sobre los cambios jurídicos y la organización de personas trans para reformar las leyes locales. Esto con el fin de facilitar el proceso de obtención de una nueva acta de nacimiento por medio de un trámite en el Registro Civil y no un juicio, como hasta entonces había sido.

Uno de los elementos que mis interlocutoras exponen con frecuencia en Facebook, son las fotografías personales. Esto permite observar, junto 
con los comentarios y los "me gusta"7 que otros usuarios dan a la imagen, las interacciones sociales en torno al género y la performatividad del mismo. Por medio de la producción y colectivización de una fotografía, podemos observar algunas prácticas que las personas trans femeninas utilizan para configurar su identidad de género.

El proceso de configuración de dicha identidad no se detiene ahí, sino que se vale también de la retroalimentación que recibe la persona por medio de los comentarios, favorables o desfavorables, para construir y compartir un discurso sobre su propia imagen y su identidad de género. Esta identidad de género a la que refiero, analizada por medio de las fotografías y de los comentarios que se hacen de ellas, se articula con otros órdenes sociales, como la clase social, la edad y la profesión, mismas que también organizan las relaciones sociales y las identidades de las personas. Este dato no es menor si queremos comprender mejor las formas en que lo trans se expresa en estos espacios virtuales y las maneras en que se gestan y reproducen las relaciones sociales. Vale la pena recordar aquí el acento que tanto Scott como Connell ponen a su definición de género: la configuración del poder y su distribución en las relaciones sociales.

Estas articulaciones entre clase social, profesión, edad y género, nos dan una idea más

7 Facebook ofrece varias herramientas para las interacciones: los comentarios, las respuestas a los mismos, los "me gusta", entre algunas otras como los emoticones (dibujos animados que expresan emociones), las imágenes adjuntas a comentarios y la opción de compartir en sus propias cuentas (biografías) las publicaciones de otros usuarios que así lo permitan (debido a los candados de seguridad y configuraciones de privacidad que algunas personas utilizan). precisa de cómo se constituyen las relaciones de poder entre las personas trans femeninas de esta investigación, otras personas no trans e instituciones. Dichas articulaciones se observan tanto en Facebook como en el resto de los espacios urbanos de la ciudad de México. Las representaciones simbólicas y los conceptos normativos sobre lo trans trascienden el orden de género y se relacionan con la clase social y la profesión. Por citar un ejemplo, en el círculo trans no tiene el mismo significado ni jerarquía una persona trans femenina que se dedica al trabajo sexual en las calles, que una que no lo hace. Tampoco tiene la misma significación una persona trans que es definida por otras personas como travesti, que una que es definida como transgénero o transexual. Las situaciones laborales y de discriminación son diferenciadas dependiendo de estas categorías identitarias y de las prácticas sociales alrededor de las mismas.

Asimismo los afectos, las coincidencias y las discrepancias se trasladan del mundo fuera de línea, al mundo virtual en Facebook. Cuando se genera un debate sobre algún tema en particular en Facebook, las personas trans femeninas que opinan toman postura. Reaccionan de acuerdo con sus emociones personales y sus ideas, pero también en relación con tensiones colectivas de las que son parte fuera de Facebook. Por ejemplo, en el círculo trans de la ciudad de México existen diversas formas de expresión de la identidad de género. Estas diferencias en expresar, comprender y explicar la identidad de género, se convierten algunas veces en discursos normativos que circulan en la red social contenidos en fotografías, memes, notas periodísticas y notas escritas por 
las propias personas trans. Las discusiones $\mathrm{y}$ conflictos personales que detonan estos materiales se expresan tanto en Facebook como en otros sitios de convivencia trans de la ciudad de México.

Facebook funciona como un espacio social que refuerza y reproduce las relaciones sociales en el ámbito local. La red de personas trans femeninas con quienes trabajé a lo largo de la investigación, es prácticamente la misma dentro y fuera de Facebook. $\mathrm{Si}$ bien algunas de mis interlocutoras establecen contacto con personas de otros países, principalmente activistas reconocidas, este contacto no se vuelve más cercano por el uso de Facebook. Quienes tienen contacto más cercano con estas activistas extranjeras, lo han tenido antes de establecer el vínculo en la red.

Sin embargo, es preciso destacar algunas particularidades de Facebook a fin de reflexionar sobre las posibilidades metodológicas de la investigación en ciencias sociales. En primer término, hay que decir que, en la mayoría de los casos, Facebook se convierte en un espacio seguro para expresar la identidad de género por medio de recursos culturales y expresivos como, por ejemplo, la fotografía (Cano, 2009). La virtualidad permite a algunas de mis interlocutoras dos situaciones muy relevantes en sus procesos identitarios. Por un lado, establecer contactos con otras personas trans que pertenecen a la misma localidad, lo cual les da la posibilidad de tejer o fortalecer una red social efectiva fuera de Facebook. Por otra parte, a algunas de ellas les permite hacer ensayos de la publicación de su identidad de género y la expresión de la misma. Este proceso, que comúnmente se conoce como "salir del clóset", sucede en un espacio controlado, seguro y relativamente privado, ya que es el usuario de Facebook quien decide qué personas forman parte de su red de amigos virtuales. Estos dos elementos, en algunos casos, son fundamentales para los procesos de configuración de la identidad de género de mis interlocutoras. Para otras, sobre todo quienes ya habían hecho pública su identidad de género antes de la aparición y desarrollo de Facebook, el reforzamiento de la red de contactos locales, personales e institucionales, es la función más recurrente y valorada. Esto sucede por medio de diversas interacciones en la red que incluyen compartir fotografías, música, videos, consejos, recetas, comentar las publicaciones de otros y dar la aprobación a las mismas por medio del botón de "me gusta" y establecer conversaciones por medio de mensajes privados, ya sea en tiempo real o no.

Pero volvamos a las preguntas centrales de este texto: ¿cómo fue posible observar y analizar estos datos en el campo de estudio? ¿Cuáles fueron las herramientas metodológicas de esta investigación etnográfica con personas trans femeninas de la ciudad de México en Facebook? A continuación me detengo en parte del proceso metodológico que llevé a cabo y en algunas de las reflexiones sobre la etnografía móvil que permiten ahondar sobre la pertinencia de investigar sobre estas sociabilidades e inventar nuevas formas de acceder a estos campos poco explorados (Gutiérrez, 2015).

\section{OBSERVAR Y PARTICIPAR EN LOS TRÁNSITOS} El método etnográfico (o etnografía) ha sido utilizado desde hace varias décadas por disciplinas como la antropología, la sociología, la ciencia política y la psicología, dando como resultado 
investigaciones situadas y profundas sobre temas diversos que competen a científicos sociales (Guber, 2004; Ingold, 2014). Sin embargo, algunas veces la etnografía ha sido minimizada y malentendida como una técnica de investigación que se suma al conjunto de herramientas utilizadas en investigaciones de corte cualitativo. El no entenderla como un método en sí mismo limita su alcance a la mera descripción detallada del contexto de estudio. Si bien las llamadas "descripciones etnográficas" enriquecen los resultados de algunas investigaciones basadas en entrevistas en profundidad, grupos focales, y otras técnicas metodológicas, la etnografía asumida de esta manera pierde algunos de los elementos que la conforman como un método de investigación complejo.

El método etnográfico exige una serie de movimientos, no necesariamente lineales, en su puesta en acción: observar, registrar, describir, cuestionar y escribir. La escritura es parte fundamental del método. De ahí la importancia del diario de campo, de las preguntas $\mathrm{y}$ de las respuestas que se van construyendo y transformando a lo largo del trabajo etnográfico, en diálogo con la teoría y con la propia experiencia del investigador.

En este sentido, la descripción forma parte fundamental de la etnografía, pero no es su única característica, ni la única contribución posible de este método a las ciencias sociales. La descripción, acompañada de un rapport sólido, la observación, el registro en el diario de campo, la reflexividad y la escritura, conforman el método. Este conjunto de técnicas da origen a textos que permiten el análisis de las relaciones sociales en distintos grupos sociales, de los cuales, ya sea de manera temporal o definitiva, el etnógrafo o la etnógrafa, forma parte (Guber, 2011).

Uno de los pilares de la etnografía es justamente la observación y el análisis de las relaciones que se gestan y desarrollan, entre los interlocutores y quien investiga, durante el trabajo de campo. La observación participante se utiliza algunas veces de manera descontextualizada del método al que originalmente pertenece, y debido a ello pierde, en ocasiones, su capacidad explicativa. Esta técnica no consiste únicamente en que el investigador "se amigue" con sus interlocutores por medio de la convivencia y la empatía, sino en que su propio papel en el campo detone relaciones sociales útiles y significativas de la realidad que observa, registra, describe, analiza y escribe.

Algunas de las interrogantes que surgieron cuando comencé a observar las interacciones en Facebook fueron: ¿cómo poner mi cuerpo y mi identidad de género en ese campo virtual del que ahora sólo participaba como voyeur? ¿Cómo darle la importancia a ese papel que tenemos los investigadores en el campo? ¿Cómo observarme a mí misma en relación con mis interlocutoras en este cuadrado de luz que cada día permanecía más horas encendido? Me parecía que no estaba observando y participando todo lo posible en ese nuevo campo. Me intrigaban muchas de las situaciones que veía pasar y también la constante referencia a este espacio en mis entrevistas y charlas en otras sociabilidades trans de la ciudad de México, pero no sabía como dirigir mi mirada, mi cuerpo y mi presencia en este espacio tan saturado de información. Me sentía 
una espía, porque mis interlocutoras sabían que yo estaba en las fiestas, en los eventos culturales, en los foros, y en todos esos espacios que compartíamos fuera del internet, pero ¿qué pasaba cuando yo ponía atención en sus interacciones en Facebook? Así que decidí hacer pública la decisión de incluir Facebook en la investigación. Esta fue la primera decisión metodológica y ética de lo que he decidido nombrar etnografía móvil. A partir de ese momento todas nuestras interacciones en Facebook cobraron otro sentido. Inclusive algunas de mis interlocutoras se acercaron por medio del chat para pedirme más información sobre mi investigación y compartir conmigo fotografías, relatos y reflexiones diversas. También comenzamos a utilizarlo como una forma de establecer nuestras citas para encuentros fuera de la red, es decir, en otros espacios de la ciudad.

Fue así que dos elementos cobraron relevancia: los tránsitos y la necesidad de acotar lo observado. Para la elaboración del concepto de etnografía móvil que expongo en este texto, la propuesta de etnografía multilocal y las reflexiones sobre la delimitación del campo de estudio en el trabajo etnográfico fueron útiles para atender la circulación de significados, objetos e identidades culturales en un tiempo-espacio difuso (Gupta y Ferguson, 1997; Comaroff y Comaroff, 1992; Marcus, 1995; Perret, 2011; Pink, 2011; Wright, 2005). En el contexto de estudio, la etnografía unilocal pierde fuerza para describir y explicar los cambios culturales y sociales contemporáneos debido a que no contempla las conexiones entre localidades o, en este caso, entre espacios urbanos. Siguiendo esta idea decidí realizar el trabajo de campo atendiendo a las conexiones y asociaciones de diversos espacios urbanos, incluyendo los virtuales, habitados y transitados por las personas trans femeninas de la ciudad.

Mi trabajo de campo era un vaivén entre el campo en línea (online) y el campo fuera de línea (off-line) (Gutiérrez, 2015). Entraba y salía todos los días de mi cuenta de Facebook con preguntas y respuestas que formulaba también en otras sociabilidades urbanas. Meses después, durante el análisis de información, me di cuenta que el movimiento fue una metáfora constante en la investigación. Como dije en un inicio, los tránsitos no sólo eran los que mis interlocutoras habían hecho y hacían respecto a su identidad de género, sino los míos propios que entraban y salían de la pantalla y me provocaban preguntas y dudas inclusive sobre mi propia identidad de género.

A partir de esta reflexión sobre los tránsitos y como una segunda decisión metodológica, opté por poner las dudas junto con mi cuerpo, que ya se había hecho presente por medio del anuncio de mi trabajo de campo en Facebook. Decidí llevar las reflexiones de campo hacia mi propia experiencia y subjetividad. Me detuve a pensar en la importancia metodológica y reflexiva de mi papel como investigadora en Facebook y retomé una pregunta que repetían mis interlocutoras con insistencia, aludiendo a mi identidad de género y a las formas de mi deseo erótico: ¿tú qué eres?

Se me ocurrió, a fin de analizar los límites aprendidos durante mi propia experiencia con el género, jugar con mi propio cuerpo y la plasticidad del género por medio del travestismo y el registro fotográfico de esta práctica, así como la circulación en Facebook de mis propias fotografías. Mis amigos 
de Facebook comenzaron a interactuar al momento en que yo compartí los materiales visuales, por medio de "me gusta" y de comentarios. Esto me permitió reflexionar de manera más tangible, más vívida, sobre lo que significa la experiencia personal de transgredir un orden social, en este caso, el orden de género. También me permitió dilucidar la relevancia de los tránsitos a los que me he referido. La gente que comentaba o gustaba de mis fotografías, era la misma gente que fuera del internet guardaba silencio sobre el tema o hablaba del mismo. Mi familia, mis amistades, mis interlocutoras. Facebook no era, de ninguna manera, una isla. Me estaba mostrando ante un público de una forma distinta que, en menor o mayor grado, ponía en cuestión la idea de quién o qué era.

Las fotos que publicaba en mi perfil me daban existencia en Facebook y ponían en acción las relaciones sociales que mantenía de manera cotidiana en este espacio urbano. De la misma forma, mis interlocutoras configuraban su identidad de género a través de la fotografía de perfil. Estas imágenes se volvieron uno de los elementos para la observación de los tránsitos de género en el ciberespacio. La idea de hacer una etnografía móvil me permitió poner en perspectiva los esencialismos recurrentes en los procesos identitarios de género, también frecuentes en la concepción que tenemos sobre la investigación, inclusive en investigaciones etnográficas. La dificultad de seguir la pista a los tránsitos de mis interlocutoras se tornó mucho más asequible en el momento en que me hice consciente de mis propios tránsitos entre lo virtual y lo no virtual, mi propia identidad dentro de la red y el carácter híbrido de mi propia investigación.
Como he dicho, la diversidad de tránsitos no alude en este trabajo sólo al género, sino a los desplazamientos teóricos y metodológicos necesarios para lograr adentrarme en un nuevo campo de estudio que tiene tantas aristas como posibles fugas y puntos ciegos. Comprender la imposibilidad de "hacerme nativa", ese punto de partida epistemológico que nos rompe la cabeza en los múltiples intentos de lograr la aceptación de nuestros interlocutores, fue desplazado por otra idea. No es lo idéntico lo que nos habla necesariamente del otro, sino el dinamismo entre lo distinto y lo similar y los discursos normativos sobre las formas de configurar nuestras identidades de género. El papel de la etnógrafa, con su cuerpo, su voz, su risa, sus dudas, su caminar, su mirada, aportó información al trabajo de campo desde sus propios tránsitos. De esta manera fue posible llevar a cabo una etnografía móvil, sin perder de vista las fotos de perfil, puntos donde las personas se fijan aunque sea de manera breve y temporal, para situarse en el mundo social compartido.

Mi propia cuenta de Facebook se convirtió en un recurso valioso para la investigación. Me permitió mantener contacto con mis interlocutoras habituales, así como la posibilidad constante de contactar nuevas interlocutoras y organizaciones que ampliaran mi red. Además fue una plataforma para estudiar la presencia y el uso del cuerpo de personas trans femeninas en espacios virtuales, sus interacciones y la influencia de estos dos aspectos en los procesos de configuración de la identidad de género de las personas trans femeninas.

Acotar el campo de estudio en esta plataforma virtual fue un desafío debido a que son muchos y 
muy diversos los elementos que permiten interactuar a las personas: fotografías, comentarios, videos y conversaciones privadas, entre otros. ¿Cómo no perderme en medio de la incesante circulación de materiales visuales y textos? A fin de resolver este reto en mi investigación, decidí primero hacer un registro etnográfico general, para después acotar los espacios y elementos que usaría en la observación y la participación. Facebook se convirtió en un diario de campo in situ, lo que me lleva a la tercera decisión metodológica para esta investigación en Facebook. A mi diario de campo "tradicional", donde registraba las observaciones fuera de Facebook, se sumó este otro diario virtual, donde me fue posible registrar y comentar la información por medio de las distintas herramientas que ofrece la red social: fechas, líneas del tiempo, mensajes privados, comentarios a mis fotos, entre muchos otros datos que hacían posible archivar en alguna medida las interacciones. Esto me permitió volver sobre la información en la misma red a lo largo del trabajo de campo con fechas de registro precisas y articuladas con otros eventos ocurridos en las mismas fechas.

Como resultado de este recorrido en mi campo virtual y de las decisiones metodológicas que he traído a cuenta, tomé otra de las decisiones importantes para esta investigación. Decidí centrarme para el análisis de la configuración de la identidad de género de mis interlocutoras, en las fotografías de perfil, los comentarios y algunos eventos que reflejaran las tensiones alrededor de los distintos discursos normativos sobre lo trans y el género, tanto dentro como fuera de Facebook. No fue posible, ni necesario para los fines de la investigación, analizar las interacciones desplegadas por medio de otras herramientas de Facebook. Las fotos de perfil y las interacciones en torno a estas dieron suficiente información para el análisis de ese proceso de configuración al que me he referido en párrafos anteriores. A través de las fotografías de perfil pude analizar el carácter performativo del género y las articulaciones de este con otros órdenes sociales como la clase social, la profesión y la edad. En las fotografías y las interacciones alrededor de ellas se pueden observar y analizar los discursos normativos sobre el género, y a través de estos, se expresan los conceptos normativos, las representaciones simbólicas y las identidades subjetivas de las personas trans femeninas de esta investigación.

\section{CONSIDERACIONES FINALES}

¿Cuáles son las aportaciones de la etnografía móvil a los estudios de género? ¿Qué la hace distinta de una etnografía tradicional? La etnografía móvil permite una nueva conceptualización del campo de investigación. En Facebook o cualquier otra red social en internet, no estamos ante un espacio situado y definido, sino ante tránsitos que nos permiten observar y analizar los procesos identitarios de las personas. El género es un proceso en continua transformación y, por lo tanto, es también un tránsito, y estudiarlo como tal en contextos caracterizados por el cambio constante aporta una nueva mirada que permite poner en cuestión los esencialismos en relación con las identidades y el género. Las fotografías de perfil que se muestran en Facebook, por ejemplo, pueden no corresponder con la imagen que la persona trans femenina muestra fuera de la red, ya sea por seguridad, porque no vive de manera permanente como mujer, o simplemente porque no lo 
desea. La imagen que hoy está en el perfil, mañana puede ser otra que muestre una faceta distinta de la persona o de su proceso de transición. De igual manera algunos de los elementos compartidos en las biografías de Facebook se van transformando conforme se agregan lecturas y comentarios de las personas que interactúan o incluso desaparecen.

Las personas trans femeninas de esta investigación habitan y transitan en Facebook por medio de un perfil en donde va quedando registrada lo que se llama su biografía, que equivale a su identidad y a su vida transcurrida en la red social. Una vez que crean su propia existencia en Facebook, comienzan a compartir información y a interactuar con otras personas que poseen perfiles similares o distintos, dependiendo el objetivo de la interacción. Entablan de esta manera una amistad virtual que pone en acción performativas particulares y recursos culturales compartidos para la configuración de la identidad de género, como la fotografía. Por medio de herramientas más específicas como el chat, las personas dan un carácter más íntimo a las relaciones que establecen en esta red social en internet.

Internet en general, y Facebook en particular, son medios de información y comunicación social que permiten a las personas trans femeninas de la ciudad de México con quienes trabajé en esta investigación, comunicarse entre ellas. Sin embargo, son también sociabilidades urbanas que abren espacios relativamente seguros en la red, donde algunas personas trans femeninas construyen una imagen de sí mismas por medio de la fotografía de perfil y de cierta información básica. Considerar Facebook como un campo en sí mismo, y en este caso, como una sociabilidad trans, hace posible observar y analizar las relaciones sociales, y con ello el orden de género y sus articulaciones con otros órdenes.

Por ahora lo que he llamado etnografía móvil me permitió dar cuenta de estas relaciones sociales y expresiones vinculadas al orden de género. Tal vez el método, las decisiones que se van tomando en los tránsitos y las técnicas implicadas en el trabajo de campo, no disten mucho de la etnografía tradicional. La observación participante, el registro en un diario de campo, la reflexividad y el cuestionamiento de mi papel como investigadora también hubieran estado presentes en una etnografía tradicional. Sin embargo, poner el acento en el movimiento, los tránsitos, los vaivenes, es ya una aportación para dislocar la mirada de quien investiga. Cuando aprendí a hacer etnografía mientras estudiaba la licenciatura, la indicación frecuente de mis profesores era dar cuenta de todo, como si fuera una fotografía: las medidas de los objetos, las dimensiones de las habitaciones, el número de personas, los colores y los nombres de las plantas, las relaciones de parentesco dibujadas en hermosas genealogías propias de museos. Sin embargo, poco se nos decía sobre la necesidad de observar y registrar el movimiento de las personas, de los animales, de los objetos. Menos aún sobre las transformaciones de las ideas, de los cuerpos, de los afectos, de las relaciones sociales y de su organización.

Aprender a mirar de otra manera, a escuchar, a oler, a tocar el campo de estudio en movimiento, a registrarlo no como una fotografía sino como una serie de movimientos complejos, puede ser una aportación suficiente para comprender el orden de género a la luz de las nuevas tecnologías. Voltear 
a ver los puentes entre lo que se ha llamado el mundo virtual y el mundo real, darles su justa dimensión, nos acerca a un análisis más complejo de cómo las personas, trans y no trans, configuramos nuestras identidades de género y las expresamos en sociabilidades contemporáneas como las redes sociales en internet. $\curvearrowright$ 


\section{BIBLIOGRAFÍA}

Aguilar Rodríguez, Daniel y Elías Said Hung (2010), "Identidad y subjetividad en las redes sociales virtuales: caso de Facebook”, en Zona Próxima, Universidad Del Norte, Colombia, núm. 12, pp. 190-207. Álvarez-Gayou, Juan Luis y Rafael Mazin (1979), Elementos de Sexología. México, Nueva Editorial Interamericana.

Barrios, David y María Antonieta García (2008), Transexualidad: la paradoja del cambio. México, Editorial Alfil.

Butler, Judith (2007), El género en disputa. El feminismo y la subversión de la identidad. España, Paidós Ibérica.

Cano, Gabriela (2009), "Inocultables realidades del deseo", en Gabriela Cano, Mary Kay Vaughan y Jocelyn Olcott (comps.), Género, poder y politica en el México posrevolucionario. México, Fondo de Cultura Económica, Universidad Autónoma Metropolitana, pp. 61-90.

Castells, Manuel (2009), Comunicación y poder. Madrid, Alianza Editorial.

Chaves Lopes, Gustavo (2013), “As redes sociais e os novos fluxos de agendamento: uma análise da cobertura da Al Jazeera sobre a Primavera Árabe”, en Palabra Clave, vol. 16, núm. 3, pp. 789-811.

Cogo, Denise y Daniel Lopes (2011), "Movimientos juveniles, medios digitales y prácticas de ciudadanía en Fortaleza (Brasil)”, en Observatorio, vol. 5, núm. 1, pp. 35-57.

Comaroff, John y Comaroff Jean (1992), Ethnography and the Historical Imagination. Boulder, Colorado, Westriew.

Connell, Raewyn (1987), Gender and Power: Society, the Person, and Sexual Politics. Stanford, California, Stanford University Press.

Domínguez, Daniel, Anne Beaulieu, Adolfo Estalella, Edgar Gómez, Bernt Schnettler y Rosie Read (2007), "Etnografía Virtual", en Forum : qualitative social research sozialforschung, vol. 8, núm. 3, consultado el 10 de agosto de 2015, URL: http://nbn-resolving.de/urn:nbn:de:0114-fqs0703E19 
Gómez, Edgar (2002), "Hacia la construcción de una metodología para el estudio de las comunidades virtuales", en Versión, núm. 12, pp. 61-78.

Gómez, Edgar y Elisenda Ardèvol (2011), "Random Images : the contexts of digital photography”, en QuAderns-E, núm. 16 (1-2), pp. 89-102.

Guber, Rosana (2004), El salvaje metropolitano: reconstrucción del conocimiento social en el trabajo de campo. Buenos Aires, Paidós.

Guber, Rosana (2011), La etnografía. Método, campo y reflexividad. Buenos Aires, Editorial Siglo Veintiuno.

Gupta, Akhil y James Ferguson (1997), “Discipline and practice: 'The Field' as site, method, and location in anthropology", en Akhil Gupta y James Ferguson (eds.), Anthropological Locations: Boundaries and Grounds of a Field Science. California, University of California Press, pp. 1-46.

Gutiérrez, Ana Paulina (2015), "Identidades trans femeninas. sociabilidades, internet, narrativas y tránsitos de género en la Ciudad de México”. México, El Colegio de México, tesis de doctorado en sociología.

Guzmán, Sandy (2013), “Redes sociales y acción política”, en Versión. Estudios de Comunicación y política, núm. 31, pp. 68-76.

Hochman, Nadav (2014), “Imagined Data Communities”, en Selfiecity, proyecto en línea (febrero):

pp. 1-3, consultado el 10 de agosto de 2015, URL: http://d25rsf93iwlmgu.cloudfront.net/downloads/ Nadav_Hochman_selfiecity.pdf

Ingold, Tim (2014), "That's Enough about Ethnography!”, en Hau: Journal of Ethnographic Theory, vol. 4, núm. 1, pp. 383-395.

Jones, Steve (1999), "Studying the Net: Intricacies and Issues”, en Steve Jones (ed.), Doing Internet Research: Critical Issues and Methods for Examining the Net, Thousand Oaks, CA, SAGE, Publications, pp. 1-29.

Machado, Jorge Alberto (2007), “Ativismo em rede e conexões identitárias: novas perspectivas para os movimentos sociais", en Sociologias, vol. 9, núm. 18, pp. 248-285. 
Manovich, Lev (2014), Selfiecity, proyecto en línea, consultado el 10 de agosto de 2015, URL: http:// www.selfiecity.net/

Marcus, George (1995), "Ethnography in/of the World System: The Emergence of Multi-Sited Ethnography", en Annual Review of Anthropology, vol. 24, pp. 95-117.

Mata, María Cristina (2002), “Comunicación, ciudadanía y poder. Pistas para pensar su articulación”, en Revista Diálogo de la Comunicación, Lima, núm. 64, pp. 65-76.

Espinar, Ramón (2015), “El espacio público y la pugna por el significado de la democracia. El debate alternativo sobre el Estado de la Nación en el movimiento 15-M", en $A C M E$, vol. 14, núm. 1, pp. 61-74.

Perret, Gimena (2011), “Territorialidad y práctica antropológica: desafíos epistemológicos de una antropología multisituada/multilocal”, en KULA. Antropólogos del Atlántico Sur, núm. 4, pp. 52-60.

Picciuolo, José Luis (1999), "Dentro y fuera de la pantalla. Apuntes para una etnografía del ciberespacio", en Leonela Cucurella (ed.), Antropología del ciberespacio. Quito, Ecuador, Abya Yala, pp. 9-22.

Pink, Sarah (2011), "Ethnography of the invisible: how to 'see' domestic and human energy", en EthnologiaEuropaea: Journal of European Ethnology, vol. 41, núm. 1, pp. 117-128.

Rodríguez, Daniel (2010), "Identidad y subjetividad en las redes sociales virtuales: caso de Facebook", en Zona Próxima, Universidad Del Norte, Colombia, núm. 12, pp. 190-207.

Salgado, Eva (2013), “Twitter en la campaña electoral de 2012”, en Desacatos, núm. 42, mayo-agosto, pp. 217-232.

Scott, Joan (2008), Género e historia. México, Fondo de Cultura Económica y Universidad Autónoma de la Ciudad de México.

Serrano, Eunate, Antonio Calleja López, Arnau Monterde y Javier Toret (eds.), (2014), 15MP2P. Una mirada transdisciplinar del 15M. España. DOI: http://dx.doi.org/10.7238/in3.2014.1

Stoller, Robert (1968), Sex and Gender: on the Development of Masculinity and Femininity. New York, Science House. 
Taibo, Carlos, Esther Vivas y Josep Atentas (2011), La rebelión de los indignados. Movimiento 15-m: Democracia real, iya!. España, Editorial Popular.

Tifentale, Alise (2014), “The Selfie: Making Sense of the 'Masturbation of Self-Image' and the 'Virtual Mini-Me"”, en Selfiecity, proyecto en línea, pp. 1-24, consultado el 10 de agosto de 2015, URL: http://d25rsf93iwlmgu.cloudfront.net/downloads/Tifentale_Alise_Selfiecity.pdf

Tong, Stephanie, Brandon Van Der Heide, Lindsey Langwell y Joseph Walther (2008), “Too much of a good thing? The relationship between number of friends and interpersonal impressions on Facebook", en Journal of Computer-Mediated Communication, vol. 13, núm. 3, pp. 531-549. DOI: 10.1111/j.10836101.2008.00409.x

Winocur, Rosalía (2006), "Internet en la vida cotidiana de los jóvenes”, en Revista Mexicana de Sociología, vol. 68 , núm. 3, pp. 551-580.

Wright, Pablo (2005), “Cuerpos y espacios plurales: sobre la razón espacial de la práctica etnográfica”, en Indiana, Berlín, Alemania, núm. 22, pp. 55-72.

Fecha de recepción: 24 de agosto de 2015

Fecha de aceptación: 21 de enero de 2016

\section{ACERCA DE LA AUTORA}

\section{ANA PAULINA GUTIÉRREZ MARTÍNEZ}

(pensardeotromodo@gmail.com)

Es doctora en ciencia social con especialidad en sociología por El Colegio de México, maestra en ciencias sociales por la Universidad de Quintana Roo y antropóloga por la Universidad Autónoma de Querétaro. Actualmente realiza una estancia posdoctoral en la facultad de Estudios Superiores de Cuautla, de la Universidad Autónoma de Morelos. Sus áreas de interés son el género, lo trans, las identidades y la lactancia materna vinculadas al estudio de las redes sociales en internet, la salud y la violencia. En su tesis doctoral trabajó las sociabilidades, internet, narrativas y tránsitos de género en la Ciudad de México. Es coautora del artículo "Mujeres mayas, género y violencia: un acercamiento”, en Rev Sal Quintana Roo (2012). 